\title{
Optimized Tension for AZ31B Thin Sheets Rolled with On-Line Heating Rolling
}

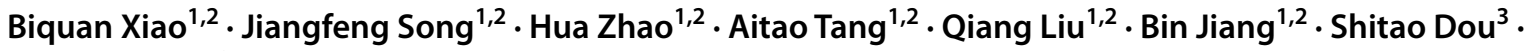 \\ Fusheng $\operatorname{Pan}^{1,2}$
}

Received: 22 June 2020 / Revised: 17 July 2020 / Accepted: 18 August 2020 / Published online: 12 October 2020

(c) The Chinese Society for Metals (CSM) and Springer-Verlag GmbH Germany, part of Springer Nature 2020

\begin{abstract}
On-line heating rolling mill which could efficiently preheat sheet and apply tensile force on both ends of the sheet along rolling direction (RD) was used to investigate the effect of tension on mechanical behavior and shape quality of magnesium sheets. For revealing the influence mechanism, many analysis techniques including optical microscope, electron backscattered diffraction, macrotexture and transmission electron microscope were performed. The shape defect, edge wave, could be eliminated under higher tension along $\mathrm{RD}$, which was attributed to more uniform distribution of microstructure and microstrain. Nevertheless, it is undesirable that the forward tensile force exceeds $3 \mathrm{kN}$ in present work because the strength decreased for high recrystallization level when the tensile force is beyond this value. Furthermore, the main deformation mode was still slip during rolling process despite of accompanying twining, e.g., double twins, but more prismatic slip activated when tensile force exceeds $3 \mathrm{kN}$. The distribution of shear bands was affected by the applied tensile force that they appear as "V" shape along RD at a low forward or backward tensile force, while they appear as reticulate shape under applied tensile force of $5 \mathrm{kN}$.
\end{abstract}

Keywords Magnesium $\cdot$ Tension $\cdot$ On-line heating rolling $\cdot$ Mechanical behavior $\cdot$ Shape quality

\section{Introduction}

Magnesium alloys have great potential in biomedical applications and 3C industries for its excellent biocompatibility, heat dissipation and high specific strength [1-4]. In addition, in the field of $\mathrm{Mg}$ ion batteries, magnesium is also an ideal battery anode material because of its high volumetric energy density [5]. In these fields, thin magnesium and magnesium

Available online at http://link.springer.com/journal/40195.

Jiangfeng Song

jiangfeng.song@cqu.edu.cn

$\triangle$ Fusheng Pan

fspan@cqu.edu.cn

1 State Key Laboratory of Mechanical Transmission, College of Materials Science and Engineering, Chongqing University, Chongqing 400044, China

2 National Engineering Research Center for Magnesium Alloy, Chongqing University, Chongqing 400044, China

3 Southwest Technology and Engineering Research Institute, Chongqing 400039, China alloy sheets are in need. For example, the magnesium alloy foils in the rechargeable magnesium ion battery application are required to be about $100 \mu \mathrm{m}$ [6]. Rolling is a promising method to produce thin sheets and foils. Unfortunately, the rolled sheets are susceptible to some shape defects such as edge-wave or center-wave [7] and the formability of magnesium alloy is relatively poor. So, there is a challenge in getting a thin magnesium sheet and foil with high quality.

Generally, the distribution of strain is always inhomogeneous during deformation processing. On the one hand, local deformation which caused strain concentration plays an important role in producing gradient structure materials $[8,9]$. On the other hand, shape defects, such as buckle and bow warping, often occur which result from the strain concentration. As longitudinal tensile stresses have an important impact on the plastic material flow in the roll gaps, accurate control of these stresses is crucial for the shape and thickness of the strip. Wang et al. [10] suggested that the applied tension can change transversal flow of metal in rolling process. It is found that applying backward and forward tension plays a critical role on reducing the thickness deviations and thus improves the quality of hot rolled steel strips [11-13]. 
In addition, the state of stress in deformation zone during rolling process was changed if larger tensile force along RD was applied. The magnesium sheets deformed by conventional rolling show strength basal texture with $c$-axis of grains titled from ND to RD. Accordingly, basal $\langle a\rangle$ and pyramidal $\langle c+a\rangle$ slip are the main deformation mode during conventional rolling with no tensile force along RD [14]. The rolled magnesium sheets did show good shape quality when applied allege tensile force along RD [15]. However, there is relatively little research about the effect of tensile force on deformation mode of magnesium during rolling.

Our previous work has demonstrated that applying tension along RD during rolling process will result in magnesium alloy sheets with good shape quality. However, the underlying reasons of the good shape quality have not been discussed in detail. Furthermore, for a potential structural material such as AZ31B sheet, it is necessary and of great importance to investigate the effect of applied tension on the mechanical properties of the sheet. Therefore, the effects of tension on the shape quality and mechanical properties of rolled AZ31B sheet were studied in detail.

\section{Experimental}

Commercial AZ31B magnesium alloy sheets with dimensions of $600 \mathrm{~mm}$ (length) $\times 120 \mathrm{~mm}$ (width) $\times 1 \mathrm{~mm}$ (thickness) were selected as initial materials. The as-received sheets show strong basal texture, seen in our previous work [16]. As shown in Fig. 1, a special warm rolling system was used in this study. It mainly consists of three systems including tensile, on-line heating and rolling system. Before rolling, work rolls were heated to and kept at $473 \mathrm{~K}$ by hot oil which flowed between work rolls and heater (Fig. 1, No. 3). The sheet was clipped by chuck (Fig. 1, No. 6) and then connected with conductor. When turning on the heating switches, the sheet was applied to circuit and heated to $523 \mathrm{~K}$ through thermal effect of electric current. The rolling system is mainly consisted of two support rolls (Fig. 1, No. 8,) and two work rolls (Fig. 1, No. 9) of $320 \mathrm{~mm}$ and $120 \mathrm{~mm}$ in diameter, respectively. Hydraulic cylinder (Fig. 1, No. 5) is an important part of the tension system. During rolling process, the chuck moved with sheet, and a certain tension along RD was generated by the hydraulic cylinder. In current work, AZ31B magnesium sheets were rolled at $15 \%$ reduction in one single pass under the rolling speed of $0.05 \mathrm{~m} \mathrm{~s}^{-1}$. Generally, in the term of shape quality of rolled sheets, the value of applied tension should be $0.3-0.5$ times of yields strength [17]. In order to investigate the effect of tension on both shape quality and mechanical behavior, the tension value was $0.2-1.1$ times of the yield strength in the present work. Additionally, the yield strength of AZ31 sheet was about $52 \mathrm{MPa}$ when tested with a strain rate of $1.0 \times 10^{-3} \mathrm{~s}^{-1}$ at $523 \mathrm{~K}$ [18]. Based on this, the tensile force was applied in a range from 1 to $6 \mathrm{kN}$ in this work. The forward tension (same with the rolling direction) and backward tension (opposite to the rolling direction) applied in this study are listed in Table 1 . Five sheets in total were rolled under various forward and backward tension.

Tensile tests in the rolling direction (RD) and transverse direction (TD) were performed with optical strain measurement on a Shimadzu mechanical testing system with an average strain rate of $8.3 \times 10^{-4} \mathrm{~s}^{-1}$ at room temperature. At least three tensile samples with a gauge length of $10 \mathrm{~mm}$ and a width of $4 \mathrm{~mm}$ prepared using discharge machining were tested.

Samples for microstructural characterization were cut out from the center of the sheet along TD, and the observation area was parallel to ND-RD plane. Microstructures were initially analyzed using an optical microscope (OM, ZEISS, Axiovert 40 MAT). The grain structure was revealed
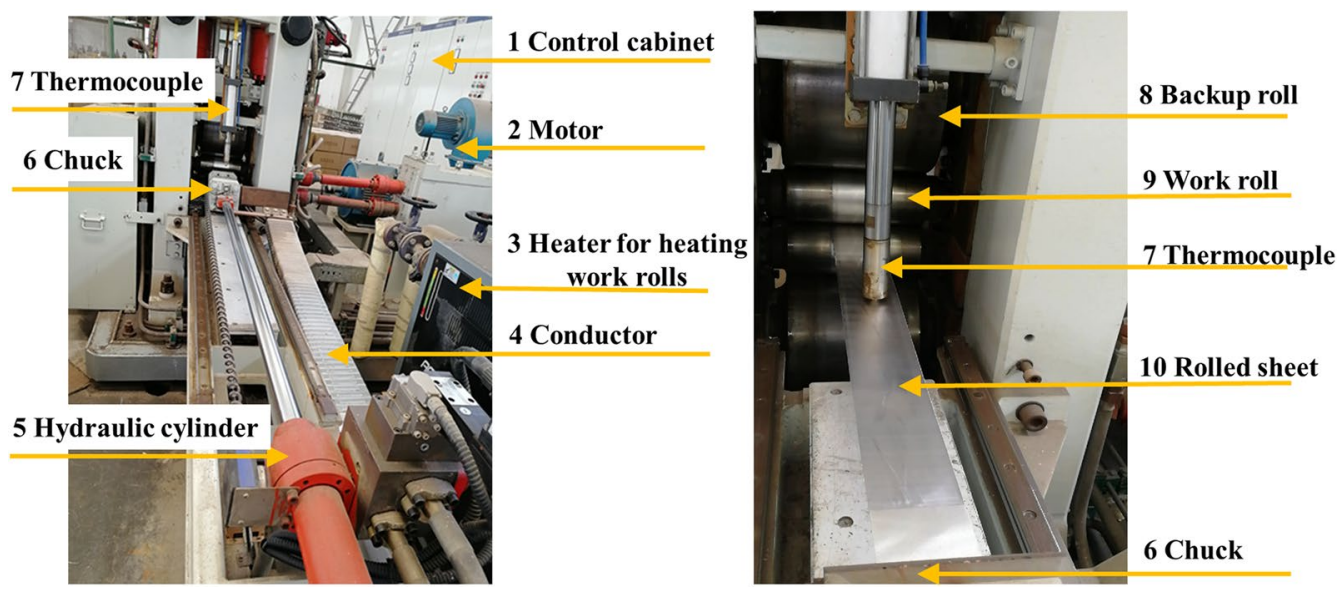

Fig. 1 Warm-rolling system 
Table 1 Applied tension in this study

\begin{tabular}{lllllc}
\hline $\begin{array}{l}\text { Sample } \\
\text { designation }\end{array}$ & $\begin{array}{l}\text { Forward force } \\
(\mathrm{kN})\end{array}$ & $\begin{array}{l}\text { Forward tension } \\
(\mathrm{MPa})\end{array}$ & $\begin{array}{l}\text { Backward force } \\
(\mathrm{kN})\end{array}$ & $\begin{array}{l}\text { Backward tension } \\
(\mathrm{MPa})\end{array}$ & $\begin{array}{l}\text { Tension } \\
\text { difference } \\
(\mathrm{MPa})\end{array}$ \\
\hline $3 / 6$ & 3 & 29.4 & 6 & 49.8 & -20.4 \\
$1 / 1$ & 1 & 9.8 & 1 & 8.3 & 1.5 \\
$3 / 3$ & 3 & 29.4 & 3 & 24.9 & 4.5 \\
$5 / 5$ & 5 & 49.0 & 5 & 41.5 & 7.5 \\
$6 / 3$ & 6 & 58.8 & 3 & 24.9 & 33.9 \\
\hline
\end{tabular}

Tension difference $=$ forward tension - backward tension by grinding and subsequent etching using a solution of ethanol $(100 \mathrm{ml})$, picric acid $(5 \mathrm{~g})$, acetic acid $(5 \mathrm{ml})$ and water $(10 \mathrm{ml})$. The crystallographic orientation of rolled sheets was investigated using electron backscatter diffraction (EBSD) in a field emission gun scanning electron microscope (JEOL, JSM-7800F, working at $20 \mathrm{kV}$ ). Sample preparation for EBSD analysis consisted of grinding on $\mathrm{SiC}$ papers of grit size 400, 600 and 1200, washing and electro-polishing. The electro-polishing process was carried out with AC2 solution at a voltage of $20 \mathrm{~V}$ and an electric current of $0.03 \mathrm{~A}$ for $60 \mathrm{~s}$ at a temperature of $-20{ }^{\circ} \mathrm{C}$. All EBSD data were analyzed using Channel 5 software. In-grain misorientation axes (IJMA) analysis was applied on specimens to reveal the deformation mode during rolling process, and the detailed IJMA analysis method could reference our previous work [16].

The samples for macrotexture and transmission electron microscopy analysis were cut from the center of the sheet along ND, and the observation area was parallel to TD-RD plane. Macrotexture of the sheet was obtained suing X-ray diffraction (XRD, Rigaku D/Max 2500 with $\mathrm{Cu} K_{\alpha}$ radiation). Transmission electron microscopy (TEM, FEI Tecnai G2 F20) was used to characterize the crystal defects. Thin foils for TEM were prepared by mechanical polishing and then ion beam thinning (GATAN, PIPS 691). TEM observation was then conducted with an accelerating voltage of $200 \mathrm{kV}$.

\section{Results}

\subsection{Optical Microstructures}

As shown in Fig. 2, shear bands like black gray lines were generated in all rolled sheet. Shear bands distribute as a "V" shape along RD in sample $3 / 6,1 / 1,3 / 3$ and $6 / 3$, while they appear as reticulate shape in sample 5/5. The shape of shear bands indicates that applying different forward force and backward force (sample 3/6 and 6/3) has little effect on shape of shear bands in ND $\times$ RD plane.

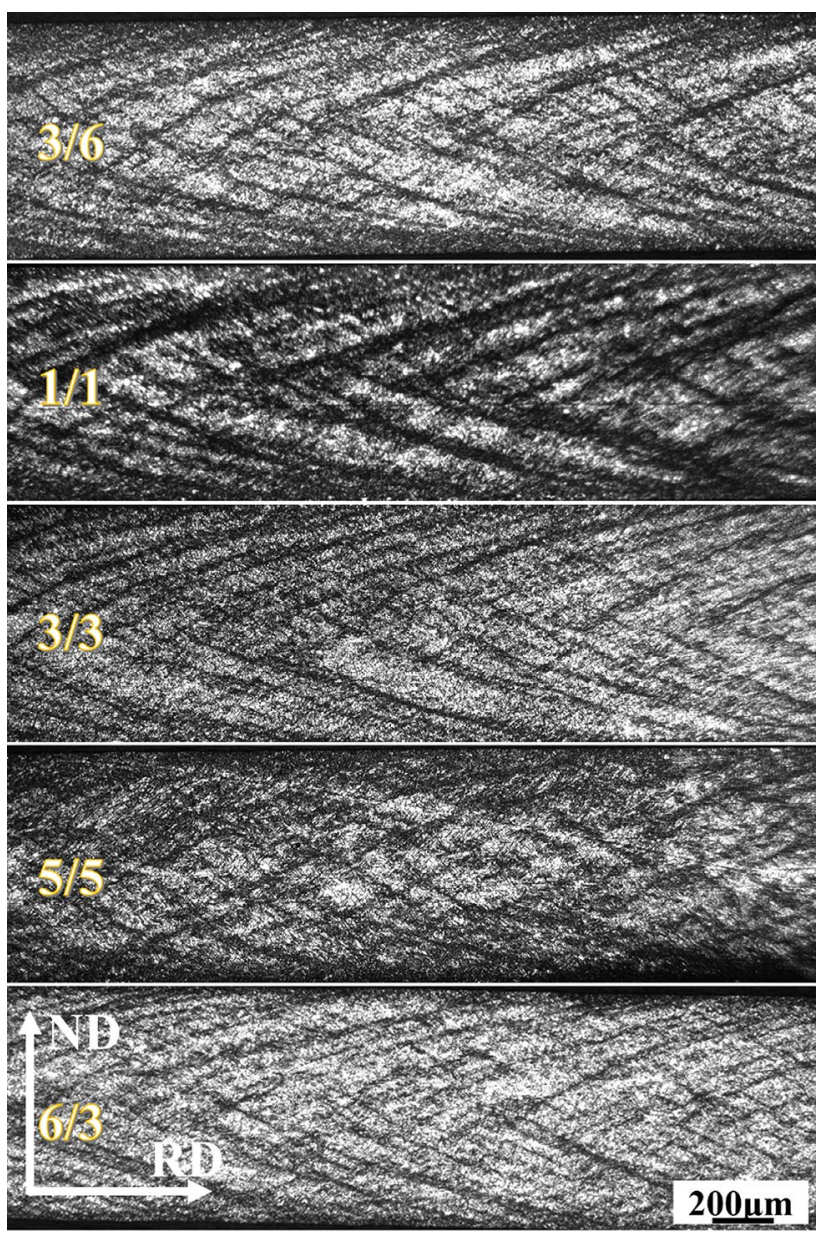

Fig. 2 Optical microstructures of rolled AZ31B sheets under various tensile forces

In the case of sample $1 / 1,3 / 3$ and $5 / 5$, the value of applied tension affects the shape of shear band as well as the microstructure. Figure 3 displays the detailed microstructures of the $1 / 1,3 / 3$ and $5 / 5$ samples. It is worth noting that the distribution of shear bands becomes denser as the force increases from 1 to $5 \mathrm{kN}$. In the case of force at $1 \mathrm{kN}$ (sample 1/1), shear bands are unevenly distributed. As the shear bands always generate in these areas where stress is 

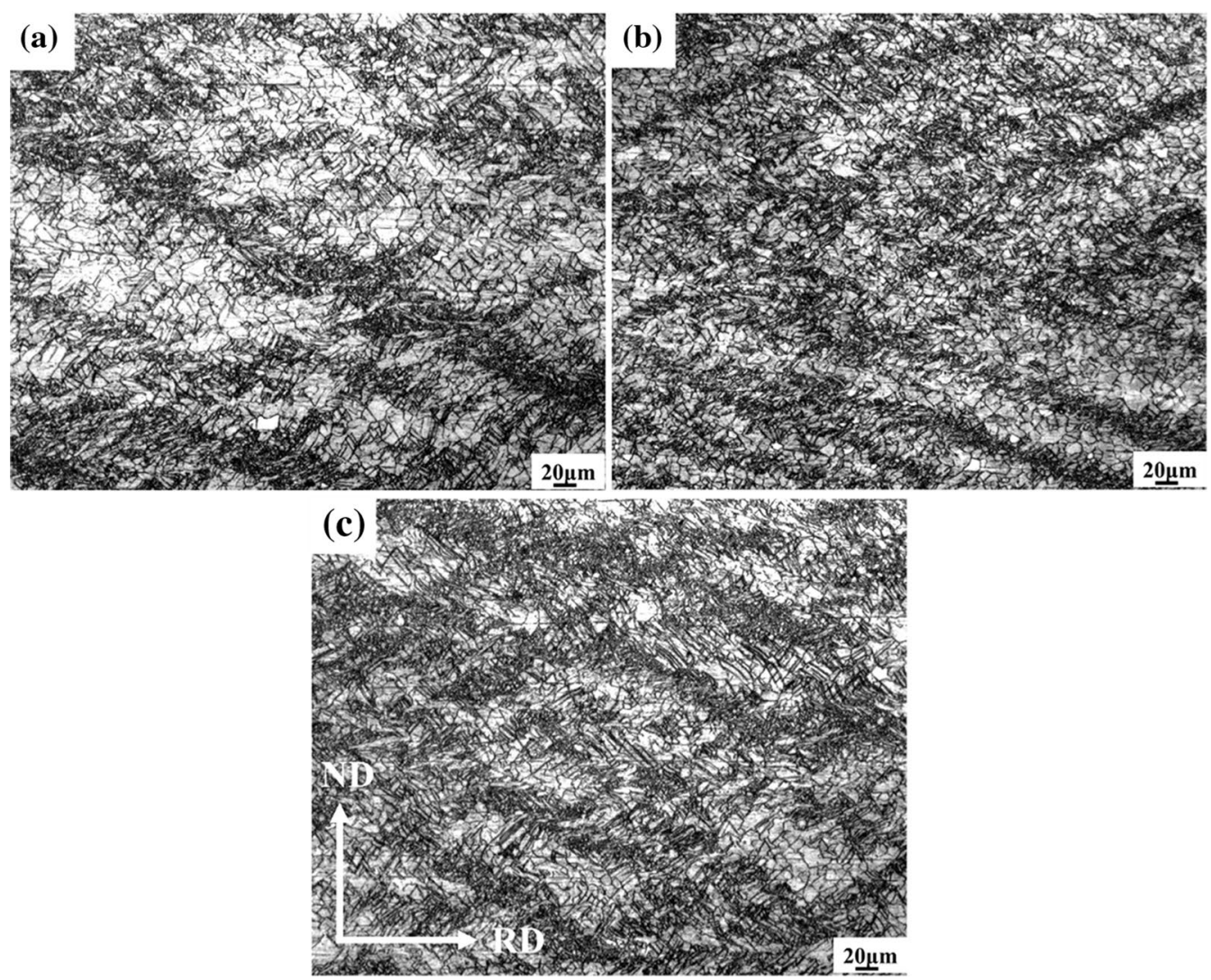

Fig. 3 Optical microstructures of rolled AZ31B sheets under the same forward and backward force of a $1 \mathrm{kN}$, b $3 \mathrm{kN}$, c $5 \mathrm{kN}$

concentrated, it is indicated that the distribution of stress is also inhomogeneous when the applied force is as small as $1 \mathrm{kN}$. Besides, the inhomogeneous distributed stress is also one of the reasons that attributes to the shape defects of rolled sheets.

As shear bands are mainly composed of recrystallized grains, the recrystallization ratio is expected to increase with denser distribution of shear bands. In high magnification metallography shown in Fig. 3, with the increase in applied tension, more equiaxed grains with smaller size were generated and distributed uniformly. Thus, it is clear that both high backward and forward forces (sample 5/5) result in homogeneous microstructure when tensile force does not exceed $6 \mathrm{kN}$.

\subsection{Tensile Properties}

The mechanical properties of 5 sheets rolled under various tensions are shown in Fig. 4. With increase in tension difference from - 20.4 MPa (sample 3/6) to $33.9 \mathrm{MPa}$ (sample 6/3), both the yield strength (YS) and ultimate tensile strength (UTS) in $0^{\circ}$ (RD) and $90^{\circ}$ (TD) gradually decrease. However, the fracture elongation (FE) in RD and TD of five sheets shows minor difference, except that the sample 3/6 in RD exhibits the lowest FE among all. In addition, the YS, UTS and FE of all the rolled sheets at TD are higher than that of RD.

The detailed YS, UTS and FE of the sheets rolled under different tension are listed in Table 2. When the forward tension is far lower than the backward tension (sample 3/6), the rolled sheet exhibits the highest strength and lowest FE in both RD and TD. When the forward tension is far higher than the backward tension (sample 6/3), the rolled sheet exhibits low strength and moderate $\mathrm{FE}$ in $\mathrm{RD}$. In the case of forward tension is close to the backward tension, the mechanical properties of sample $1 / 1,3 / 3$ and $5 / 5$ show a better balance of strength and ductility than that of high difference of backward and forward tension (sample $3 / 6$ and 6/3).

In addition, with increase in forward and backward tensile force from 1 to $5 \mathrm{kN}$, the YS and UTS in RD decrease from $233.1 \pm 3.2 \mathrm{MPa}$ and $274.1 \mathrm{MPa} \pm 1.9$ to $216.2 \pm 3.6 \mathrm{MPa}$ and $264.5 \pm 2.1 \mathrm{MPa}$, respectively. In $\mathrm{TD}$, these strengths decrease from $274.4 \pm 2.5 \mathrm{MPa}$ and $301.5 \pm 2.3 \mathrm{MPa}$ to $250.1 \pm 3.2 \mathrm{MPa}$ and $279.8 \pm 1.6 \mathrm{MPa}$, respectively. However, the strength difference in sample $1 / 1$ and $3 / 3$ is quite small. 
Considering both the optical microstructures and tensile behavior of rolled sheets, equal forward and backward tensile force is recommended to be applied in the on-line heating rolling of AZ31 sheets with a thickness of $1 \mathrm{~mm}$. Thus, the following analysis mainly focuses on the sample $1 / 1$, $3 / 3$ and $5 / 5$.

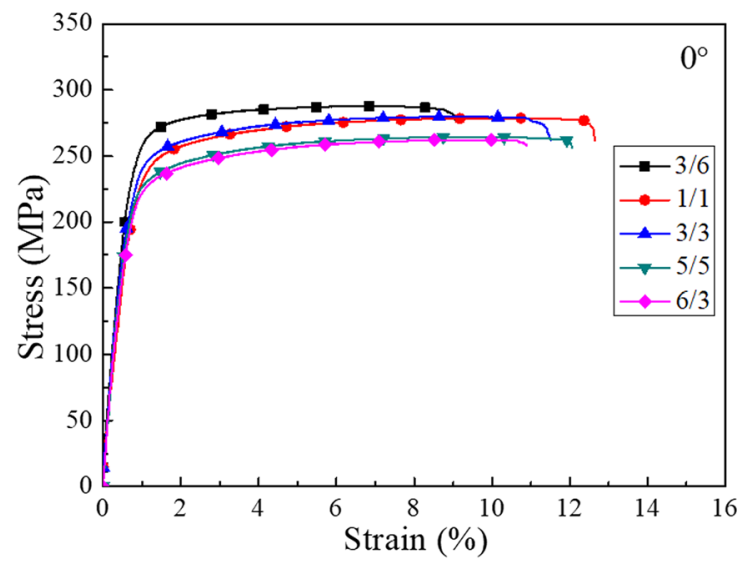

\subsection{Shape Quality of Rolled Sheet}

Shape defects, such as buckle and bow warping shown in Fig. 5a [17], often occur in conventional rolled sheets. Some of the defects needed to be eliminated by post-stretching. In the current study, good shape quality of the magnesium alloy sheet was achieved by applying force above $3 \mathrm{kN}$ along RD with the on-line heating rolling. As shown in Fig. 5b, when

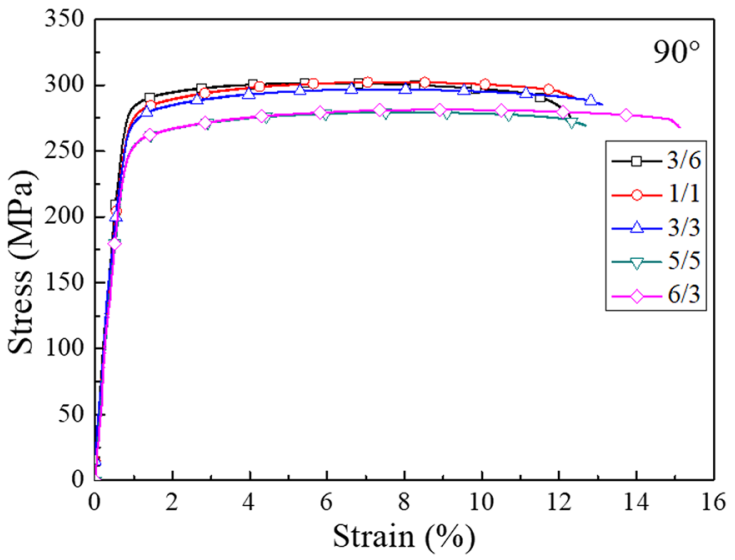

Fig. 4 Stress-strain curves in $0^{\circ}$ and $90^{\circ}$ directions at room temperature of AZ31B sheets rolled under vision tension

Table 2 Tensile properties at room temperature of AZ31 sheets rolled at various tensions

\begin{tabular}{|c|c|c|c|c|c|c|}
\hline \multirow[t]{2}{*}{ Samples } & \multicolumn{2}{|l|}{ YS (MPa) } & \multicolumn{2}{|l|}{ UTS (MPa) } & \multicolumn{2}{|l|}{ FE $(\%)$} \\
\hline & $0^{\circ}$ & $90^{\circ}$ & $0^{\circ}$ & $90^{\circ}$ & $0^{\circ}$ & $90^{\circ}$ \\
\hline $3 / 6$ & $252.6 \pm 6.9$ & $280.3 \pm 6.9$ & $286.5 \pm 1.4$ & $302.3 \pm 2.1$ & $9.3 \pm 0.3$ & $12.2 \pm 1.5$ \\
\hline $1 / 1$ & $233.1 \pm 3.2$ & $274.4 \pm 2.5$ & $274.1 \pm 1.9$ & $301.5 \pm 2.3$ & $12.3 \pm 0.7$ & $12.3 \pm 0.9$ \\
\hline $3 / 3$ & $230.3 \pm 2.5$ & $269.2 \pm 3.5$ & $269.5 \pm 4.1$ & $297.1 \pm 1.9$ & $11.3 \pm 1.1$ & $13.1 \pm 1.2$ \\
\hline $5 / 5$ & $216.2 \pm 3.6$ & $250.1 \pm 3.2$ & $264.5 \pm 2.1$ & $279.8 \pm 1.6$ & $11.9 \pm 1.6$ & $12.6 \pm 1.5$ \\
\hline $6 / 3$ & $216.9 \pm 1.9$ & $252.6 \pm 2.5$ & $263.6 \pm 1.6$ & $281.4 \pm 0.7$ & $11.5 \pm 2.5$ & $13.8 \pm 1.8$ \\
\hline
\end{tabular}
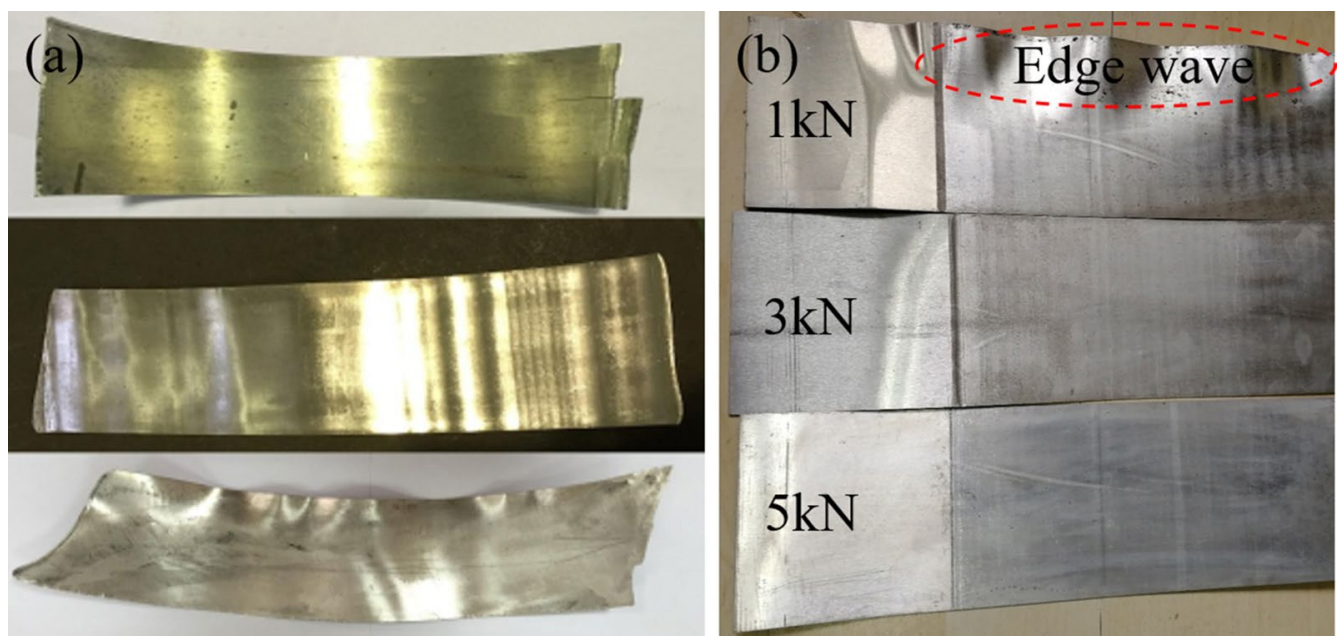

Fig. 5 Shape quality of rolled sheets by a conventional rolling [17], b on-line heating rolling 
the tensile force is $1 \mathrm{kN}$, edge wave is clearly observed. While edge wave is not visible, the tensile force is 3 and 5 $\mathrm{kN}$. As a result, this on-line heating rolling technology is beneficial for enhance the shape quality without post-treatments. Considering both mechanical properties and shape quality, equal forward and backward tensile force of $3 \mathrm{kN}$ is recommended for producing AZ31B sheets with on-line heating rolling under $523 \mathrm{~K}$.

\subsection{Grain Orientation Distribution}

Figure 6 shows the macrotexture of various rolled samples. As shown in (0002) pole figure, although the applied tensile force increases from 1 to $5 \mathrm{kN}$, there is no obvious difference in grain orientation between these rolled samples and typical strong basal texture is formed in all rolled samples. The maximum texture intensity of them is $10-12$, and basal pole splits toward RD. Such texture results in the higher YS and UTS in TD than RD [16]. Particularly, the texture intensity decreases from 11.5 to 10.1 when the applied tensile force increases from 1 to $3 \mathrm{kN}$, while it increases to 11.9 when further increasing the tensile force to $5 \mathrm{kN}$. There is no linear relationship between macrotexture intensity and applied tension.

In addition, grain orientation was also investigated through EBSD. As shown in (0002) pole figure (Fig. 7a-c), the grain orientation also presents typical basal texture. With the increase in applied tension, the recrystallization ratio $\left(f_{\text {DRX }}\right)$ increases (Fig. $7 d$ ). Specially, when the tensile force is $5 \mathrm{kN}$, the recrystallization ratio reaches $15.2 \%$. It is worth noting that the texture intensity does not decrease with increase in degree of recrystallization. When the tensile force increases from 3 to $5 \mathrm{kN}$, the recrystallization ratio increases from $10.8 \%$ to $15.2 \%$, but texture intensity slightly increases. In addition, as shown in Fig. 7e, $\{10-12\}$ extension twins, $\{10-11\}$ contraction twins and $\{10-11\}-\{10-12\}$ secondary twins were observed in all rolled sheets, and secondary twins are dominant.

The internal microstructures of rolled sheets at $3 \mathrm{kN}$ and $5 \mathrm{kN}$ were observed by TEM, and bright-field images are shown in Fig. 8. As shown in Fig. 8a, b, many fine second phase particles uniformly distributed and dislocation walls

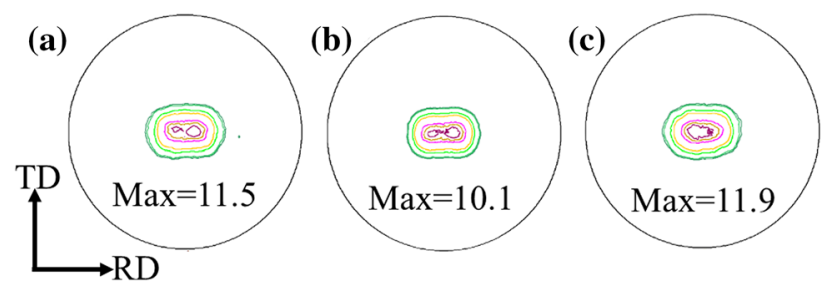

Fig. 6 (0002) pole figures of rolled samples at various tensile forces: a $1 \mathrm{kN}$; b $3 \mathrm{kN}$; c $5 \mathrm{kN}$ were formed after rolling at the tensile force of $3 \mathrm{kN}$. These images in Fig. 8c, d were taken with an incident electron beam direction of [11 $\overline{2} 0]$ under a two-beam diffraction condition with $g=0002$ and $g=01 \overline{1} 0$. The basal plane trace is indicated with a black solid line. Obviously, using the $g \cdot b$ criterion, the invisible dislocations in Fig. $8 \mathrm{c}$, visible in Fig. 8d, were found to be of the $\langle a\rangle$ type. Because the majority of dislocation segments in Fig. $8 \mathrm{~d}$ are parallel to the basal-plane trace, most dislocations are basal $\langle a\rangle$ dislocations, as indicated by green arrows. However, some $\langle a\rangle$ dislocation segments in Fig. 8d extend out of basal-plane trace, indicating that the basal dislocations conduct cross-slip from basal plane to non-basal plane, as marked by red arrows.

\section{Discussion}

\subsection{Effect of Applied Tension on the Shape of Rolled Sheet}

Shape defects of rolled sheets, such as center wave, edge wave, buckle and so on, are mainly induced due to inhomogeneous deformation. Specially, edge wave occurs when the reduction of edge part is higher than that of middle part. While by current rolling system, edge wave of rolled sheets could be eliminated when appropriate tension was applied on the both ends along RD during rolling process. This implies that the tension applied along RD effectively improves the homogeneity of deformation along TD. Generally, during rolling process, the sheet extends along $\mathrm{RD}$ with decrease in thickness. The improved shape quality may be related to that the flow velocity difference among different positions along TD in deformation zone is smaller when the applied tension is larger, which enhances the uniformity of deformation.

The distribution of microstrain helps to understand the formation of edge wave. As shown in Fig. 9a, in all rolled sheets, the local areas with coarse grains exhibit larger microstrain than these with fine grains. Figure $9 \mathrm{~b}$ shows the statistical results of microstrain of all rolled sheets. The frequency shows a peak value of 0.11 and 0.09 at the microstrain of 0.35 when the tensile forces are $3 \mathrm{kN}$ and 5 $\mathrm{kN}$, respectively, while the peak shifts to 0.07 at the microstrain of 0.55 when tension force reduces to $1 \mathrm{kN}$. Thus, the frequency of microstrain values over 0.55 (right side of the dotted line in Fig. 9b) at $1 \mathrm{kN}$ is larger than that of $3 \mathrm{kN}$, and the lowest is that of $5 \mathrm{kN}$. This implies that the larger the tensile force the smaller the possibility to generate large microstrain. According to the statistical results of microstrain shown in Fig. 9 and the microstructure shown in Fig. 3, the larger the tensile force, the more uniform the 

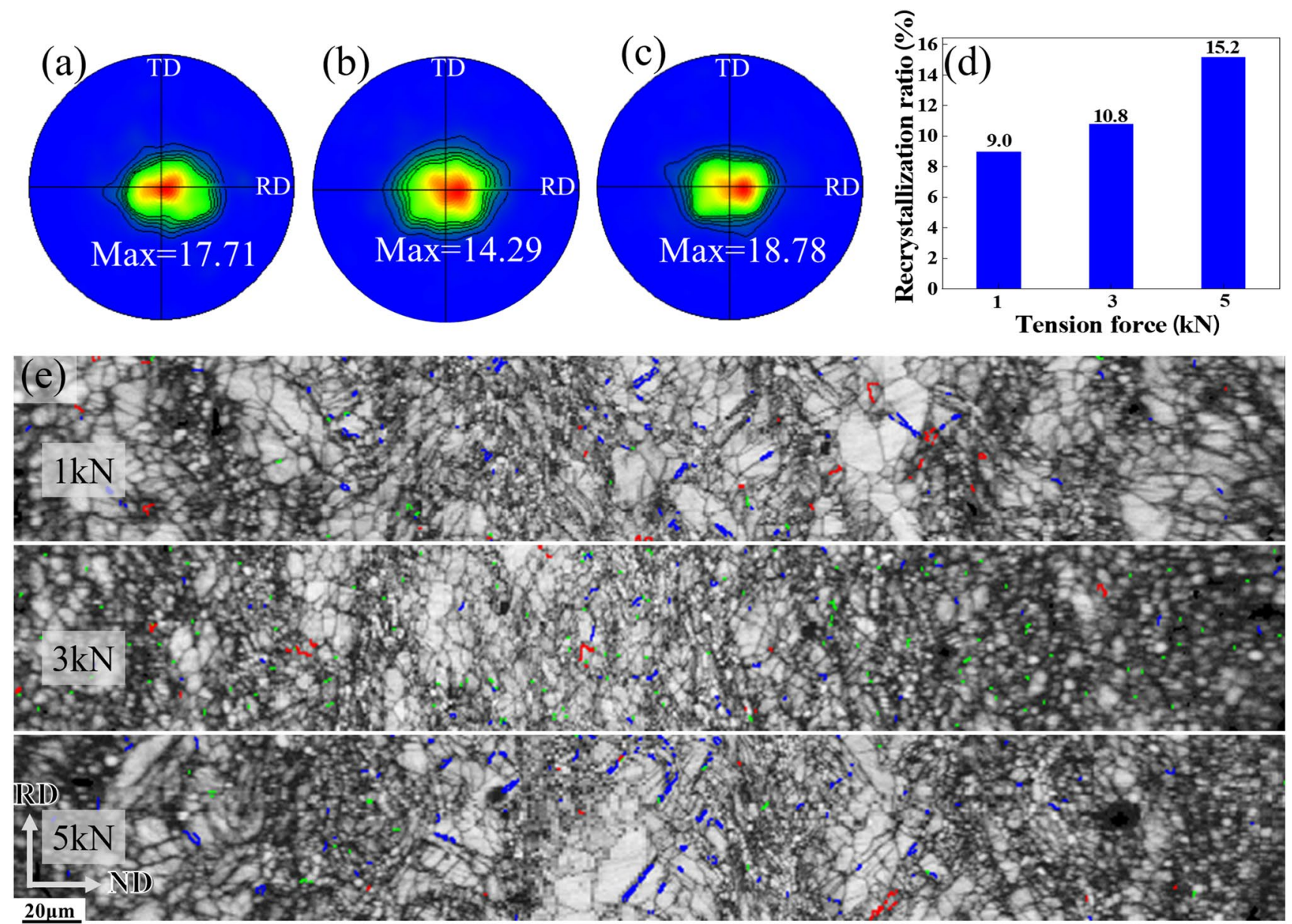

\begin{tabular}{llllll} 
Types of twins & Misorientation & Legend & \multicolumn{3}{c}{ Area fraction in rolled sample } \\
& angle/axis & $1 \mathrm{kN}$ & $3 \mathrm{kN}$ & $5 \mathrm{kN}$ \\
\hline$\{10-12\}$ extension twin & $\mathbf{8 6}^{\circ}<1-210> \pm 5^{\circ}$ & & $0.2 \%$ & $0.1 \%$ & $0.1 \%$ \\
$\{10-11\}$ contraction twin & $5^{\circ}<1-210> \pm 5^{\circ}$ & & $0.1 \%$ & $0.3 \%$ & $0.1 \%$ \\
$\{10-11\}-\{10-12\}$ secondary twin & $38^{\circ}<1-210> \pm 5^{\circ}$ & & $0.6 \%$ & $0.2 \%$ & $0.9 \%$
\end{tabular}

Fig. 7 (0002) pole figures of various rolled sheets at a $1 \mathrm{kN}, \mathbf{b} 3 \mathrm{kN}, \mathbf{c} 5 \mathrm{kN}$, d recrystallization ratio, e twins distribution figures

deformation, which hinder the formation of shape defects of rolled sheets.

\subsection{Effect of Applied Tension on the Tensile Properties of Rolled Sheet}

As shown in Table 2, the sample 5/5 exhibits the lowest yield strength and ultimate tensile strength. The pass reduction, rolling force, texture intensity and recrystallization ratio at different tensile force are listed in Table 3. The texture intensity of the rolled sheets hardly changes as the tensile force increases, indicating that the texture is not the dominant factor to the decreased yield strength. Thus, it is expected that the decreased yield strength is mainly due to the high recrystallization ratio.

Higher recrystallization ratio is related to higher pass reduction and non-basal slip activating during rolling process. As shown in Table 3, the pass reduction increases around $2 \%$ and rolling force decreases from 185 to $151 \mathrm{kN}$ when the tensile force increases from 1 to $5 \mathrm{kN}$. Moreover, it may be related to the change in stress state of deformation zone under rolling process with various tensions. The stress is mainly compressive stress inside material at conventional rolling process in $\mathrm{RD}$, while it changes into tensile stress when a larger external tension is applied at both ends of the rolled sheet, reducing the rolling force and increasing pass reduction. 

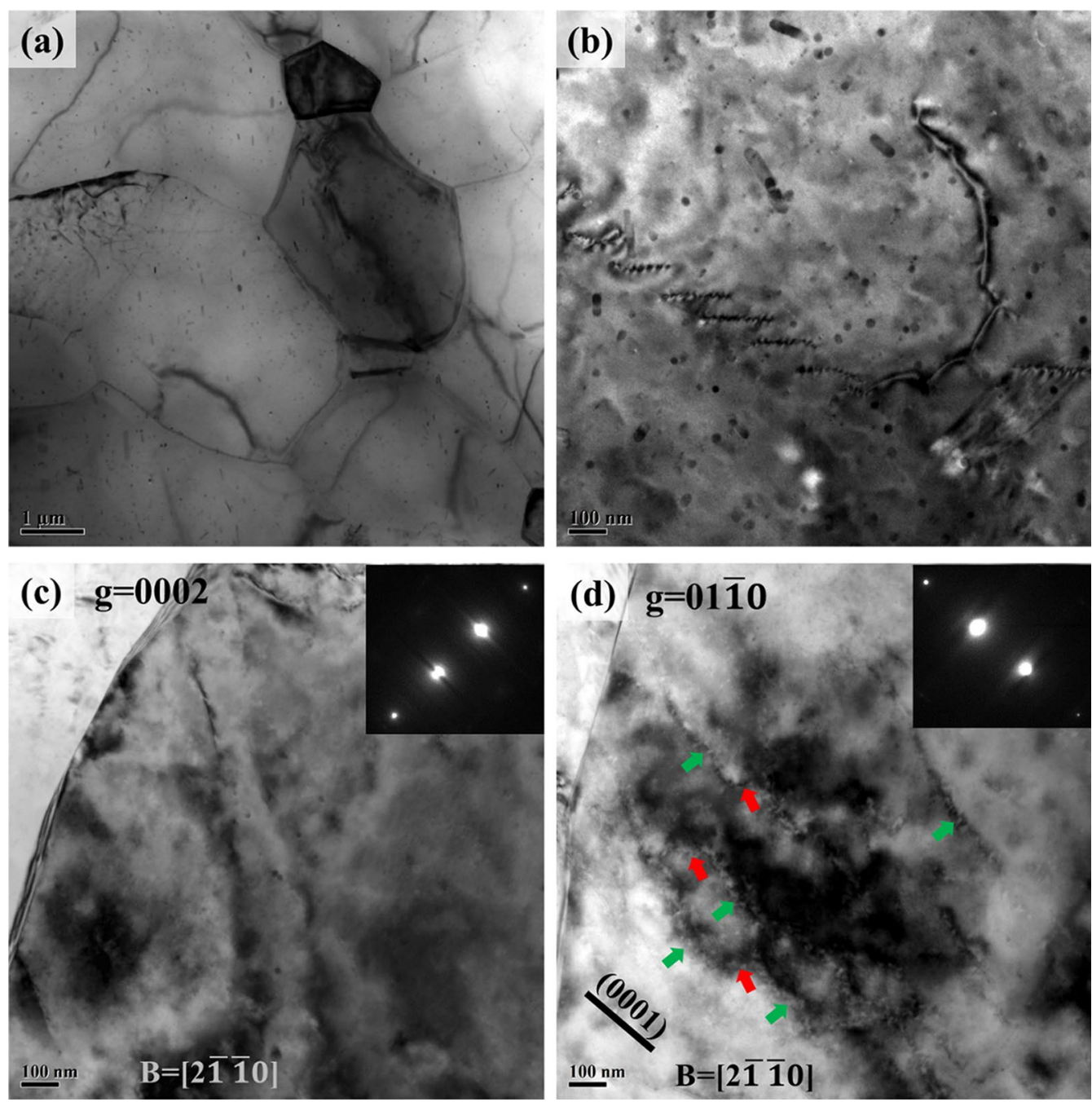

Fig. 8 TEM images of rolled sheets at different tensile force, a, b $3 \mathrm{kN}, \mathbf{c}, \mathbf{d} 5 \mathrm{kN}$

Although some twins were produced, the fraction of twins is very small (Fig. 7e). Thus, slip is the main deformation mode. On the one hand, basal dislocations conduct cross-slip at the tensile force of $5 \mathrm{kN}$ (Fig. 8d); on the other hand, the action of large tensile force along RD is favored for activating prismatic slip. As shown in Fig. 10, when applied tensile force is more than $3 \mathrm{kN}$, bending of crystal lattice under the action of slip takes place about a $<0001>$ axis shown in red circle, meaning $\{01-10\}<-2110>$ slip mode was activated. What is more, when the sheet with strength basal texture was experienced tensile deformation along RD, the distribution of strain was also reticulate [19]. It consists with the distribution of shear bands in present work under tensile force of $5 \mathrm{kN}$. When loading force in the direction perpendicular to $c$-axis, prismatic slip is the main deform mode, which was approved by both experimental [20] and simulation [21] research. So, prismatic slip was activated when applied tensile force of $5 \mathrm{kN}$. Li et al. [22] pointed out when deformation mechanisms is $\langle c+a>$ slip, DRX is greatly enhanced, since cross-slip and climb take place more readily than other slip systems, and thus, the formation of high angle boundaries is easier, while $<c+a>$ slip was activated in all rolled sheets based on macrotexture feature tilting toward RD and IJMA analysis shown in Fig. 10. So, higher recrystallization ratio at tensile force of $5 \mathrm{kN}$ maybe results from the activation of prismatic slip.

During recrystallization process, dislocation cells develop into subgrain and finally formed high angular equiaxed grains, reducing the dislocation density. So, with increase in the recrystallization ratio, the dislocation density decreases and dislocation strengthening markedly weakened. This is the main reason of low yield strength of sheet rolled at tensile force of $5 \mathrm{kN}$. In this study, kernel average misorientation (KAM) map is utilized to investigate the dislocation density of sheets rolled with different tension. In many researches, the kernel average misorientation (KAM) value 

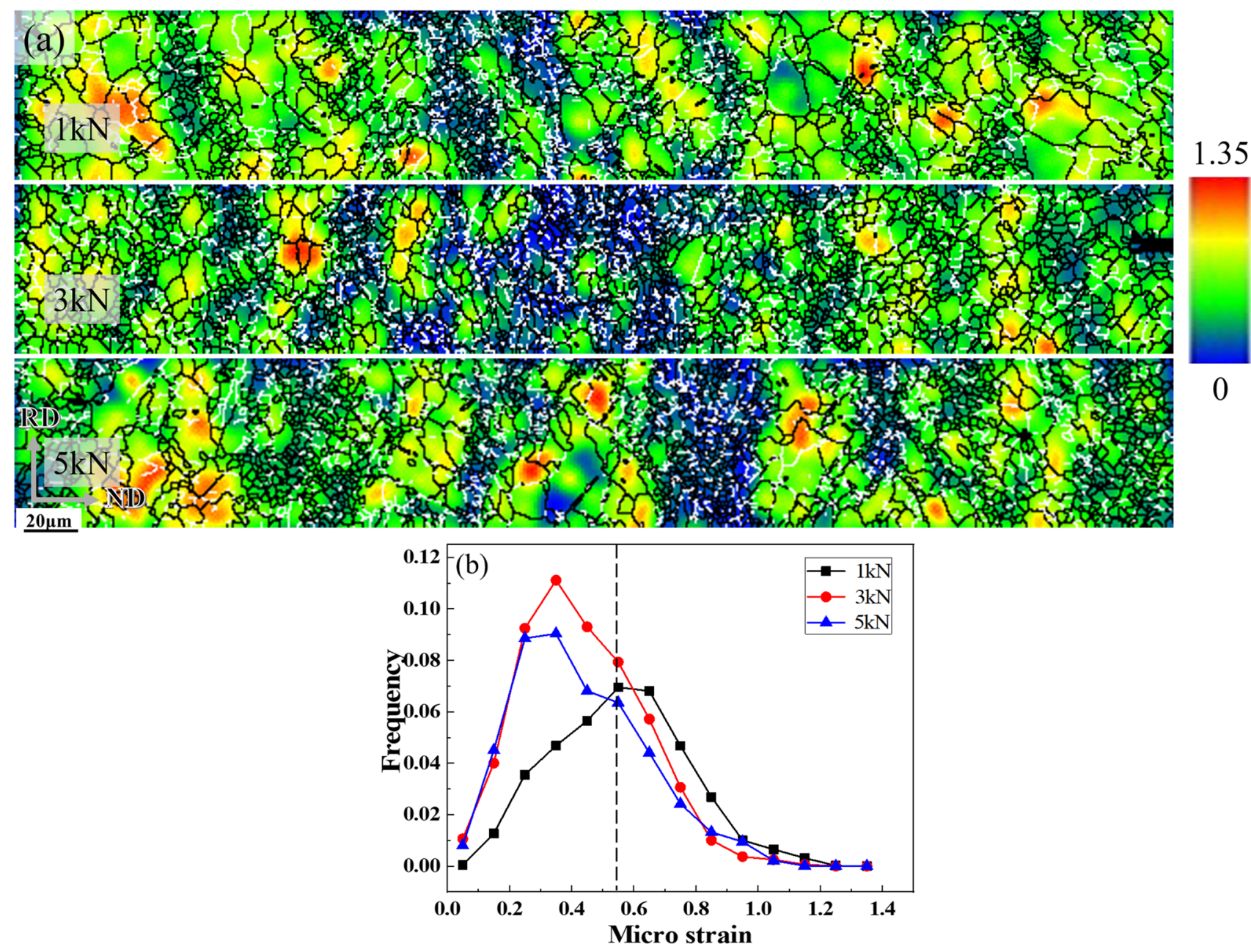

Fig. 9 a Micro-strain maps, b the statistical results of microstrain

Table 3 Pass reduction, rolling force, texture intensity and recrystallization ratio

\begin{tabular}{lllllc}
\hline Samples & $\begin{array}{l}\text { Final thickness } \\
(\mathrm{mm})\end{array}$ & $\begin{array}{l}\text { Pass reduction } \\
(\%)\end{array}$ & $\begin{array}{l}\text { Rolling force } \\
(\mathrm{kN})\end{array}$ & $\begin{array}{l}\text { Texture } \\
\text { intensity }\end{array}$ & $\begin{array}{l}\text { Recrystallization } \\
\text { ratio }(\%)\end{array}$ \\
\hline $1 / 1$ & 0.837 & 16.3 & 185 & 11.5 & 9.0 \\
$3 / 3$ & 0.838 & 16.2 & 180 & 10.1 & 10.8 \\
$5 / 5$ & 0.817 & 18.3 & 151 & 11.9 & 15.2 \\
\hline
\end{tabular}

was successfully used to evaluate the geometrically necessary dislocations (GND) density, such as the study on tensile anisotropy of a metastable beta titanium alloy [23], influence of $\mathrm{Fe}$ addition on annealing behaviors of a phosphorus [24], and deformation behaviors and cyclic strength assessment of AZ31B [25]. GND density is generally proportional to KAM value [26].

The KAM maps of sheets rolled at tensile force of 1, 3 and $5 \mathrm{kN}$ are presented in Fig. 11. These maps are evenly divided into 5 parts along ND and marked as N1-N5. Figure $11 \mathrm{~b}-\mathrm{d}$ is the local misorientation average angle distribution of sheets rolled under tensile force of 1,3 and $5 \mathrm{kN}$, respectively. When the force is 1 and $3 \mathrm{kN}$, the average KAM value is 1.33 and 1.38 . The KAM reduces to 1.25 when the force is $5 \mathrm{kN}$. This means that the dislocation density is lowest at an applied tensile force of $5 \mathrm{kN}$ and the highest at force of $3 \mathrm{kN}$. In addition, at a tensile force of $5 \mathrm{kN}$, the difference between these average KAM values of the 5 parts is small compare to that at the tensile force of $1 \mathrm{kN}$ and $3 \mathrm{kN}$, as shown in Fig. 11e. This indicates that the distribution of dislocation is more uniform at sample 5/5.

As shown in Table 2, the yield strength in $90^{\circ}$ is higher than that in $0^{\circ}$. This is mainly related to the distribution of texture. Figure 12 shows the distribution of Schmid factor 


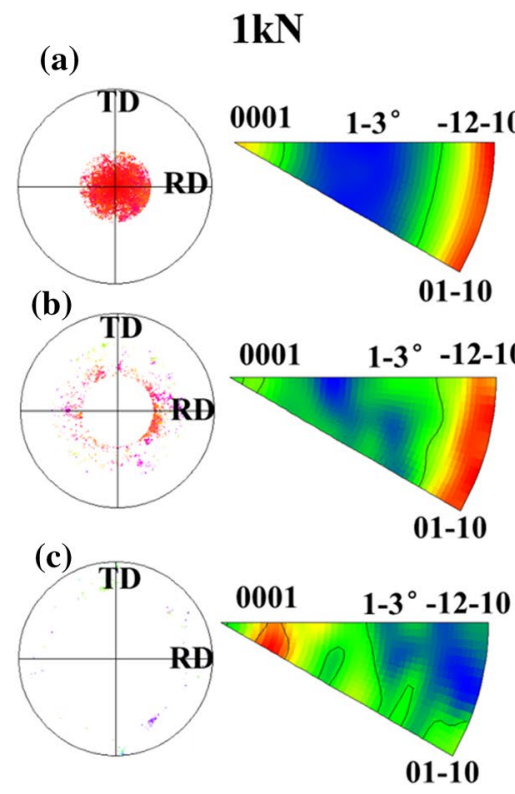

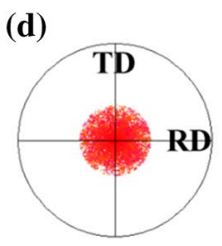
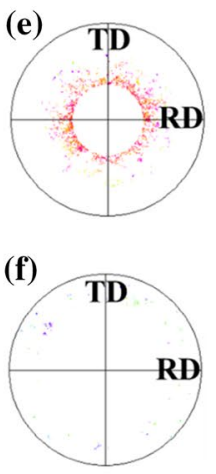

$3 \mathrm{kN}$
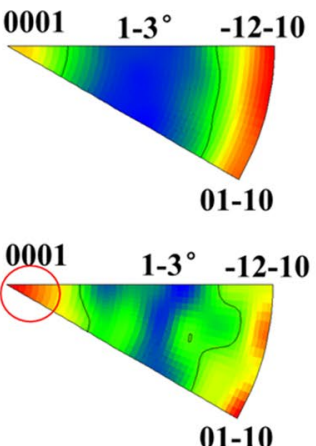

01-10

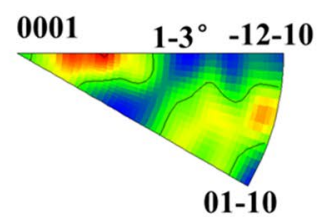

$5 \mathbf{k N}$
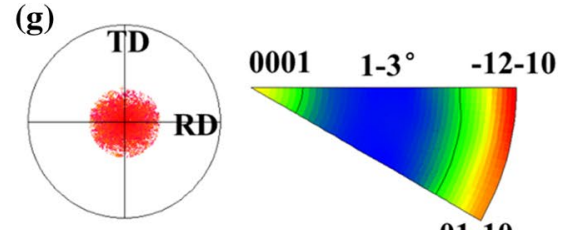

(h)
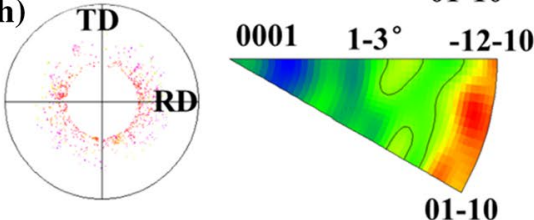

(i)
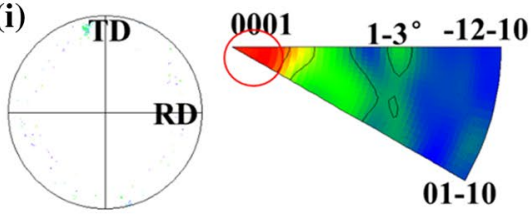

Fig. 10 IJMA analysis of grains with various angles between their $c$-axis and ND, a-c $0^{\circ}-30^{\circ}, \mathbf{d}-\mathbf{f} 30^{\circ}-60^{\circ}, \mathbf{g}-\mathbf{i} 60^{\circ}-90^{\circ}$

of basal slip during tensile along $0^{\circ}$ and $90^{\circ}$ for these sheets rolled at tensile force of 1,3 and $5 \mathrm{kN}$. For all sheets, the average Schmid factor in $90^{\circ}$ is larger than that in $0^{\circ}$. Therefore, according to equation $\sigma_{\mathrm{s}}=\tau_{\mathrm{c}} / m$, where $\sigma_{\mathrm{s}}$ is yield strength of single crystal, $\tau_{\mathrm{c}}$ is critical resolved shear stress, and $m$ is Schmid factor, yield strength of single crystal is in inverse proportion to average Schmid factor. Thus, the yield in $90^{\circ}$ is higher than that in $0^{\circ}$.

\section{Conclusions}

The present work studied the effect of tension on shape quality and mechanical properties of AZ31B sheet prepared by on-line heating rolling at $523 \mathrm{~K}$. Conclusions are as follows:

1. Combining the shape quality and mechanical properties of rolled sheets, a tensile force of $3 \mathrm{kN}$ is proposed to be the best parameter for on-line heating rolling of
AZ31B sheets at $523 \mathrm{~K}$. Edge wave is successfully eliminated without post-treatment. The yield strength, ultimate tensile strength and fracture elongation at rolling direction are 230.3 $\mathrm{MPa}, 269.5 \mathrm{MPa}$ and $11.3 \%$, respectively.

2. With increase in tension difference, the strength obviously decreases but fracture elongation slightly increases. A good balance between strength and ductility is achieved at tensile force of $3 \mathrm{KN}$.

3. Higher tension along RD promotes the activation of nonbasal slip and increases deformation degree, resulting in higher recrystallization degree and uniformly distributed microstrain along ND.

4. Shear bands distribute as "V" shape along rolling direction in these sheets rolled at tensile force of 1 and $3 \mathrm{kN}$, while they appear as reticulate shape when the tensile force is $5 \mathrm{kN}$ which indicates a more uniform microstructure at high tension. 

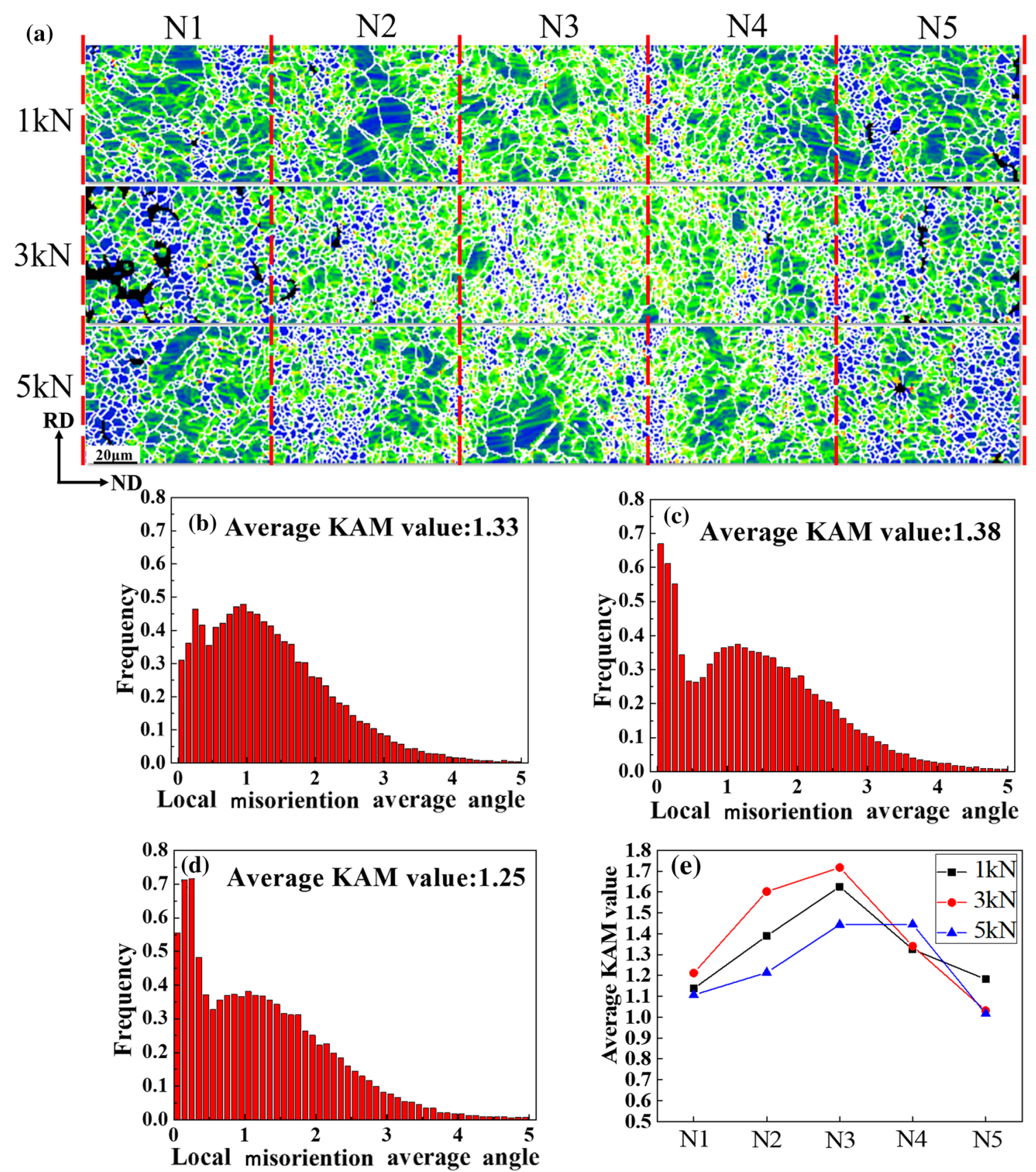

Fig. 11 a Kernel average misorientation (KAM) maps divided evenly into 5 areas in the ND; b-d the local misorientation average angle distribution of rolled sheets under different tension: b $1 \mathrm{kN}, \mathbf{c} 3 \mathrm{kN}, \mathbf{d} 5 \mathrm{kN}$; e the average KAM value distribution of the five area (N1-5) from (a) 

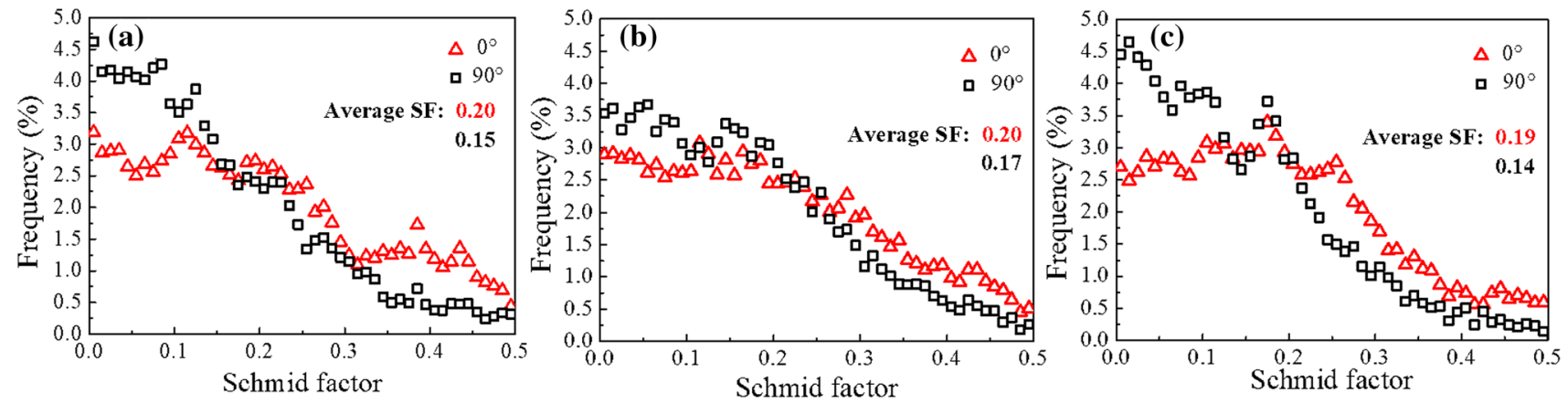

Fig. 12 Distribution of Schmid factor of basal slip during tensile along $0^{\circ}$ and $90^{\circ}$ for rolled sheets deformed at various tensile forces: a $1 \mathrm{kN}$, b 3 $\mathrm{kN}, \mathbf{c} 5 \mathrm{kN}$

Acknowledgements This work is financially supported by the National Science Foundation for Young Scientists of China (No. 51701027), the National Key Research and Development Program of China (No. 2017YFF0209100), the National Defense Basic Scientific Research Program of China, the Fundamental Research Funds for the Central Universities Project (No. 2020CDJQY-A002) and the Shanghai Rising-Star Program (No. 18QB1401400).

\section{References}

[1] N. Sezer, Z. Evis, S.M. Kayhan, A. Tahmasebifar, M. Koc, J. Magnes. Alloys 6, 23 (2018)

[2] S.T. Zhang, F.J. Wu, Surf. Interface Anal. 43, 752 (2011)

[3] K.B. Nie, X.J. Wang, K. Wu, L. Xu, M.Y. Zheng, X.S. Hu, J. Alloys Compd. 509, 8664 (2011)

[4] P. Amaravathy, T.S.S. Kumar, J. Magnes. Alloys. 7, 584 (2019)

[5] B. Li, R. Masse, C.F. Liu, Y. Hu, W.S. Li, G.Q. Zhang, G.Z. Cao, Energy Storage Mater. 22, 96 (2019)

[6] D. Schloffer, S. Bozorgi, P. Sherstnev, C. Lenardt, B. Gollas, J. Power Sources 367, 138 (2017)

[7] K. Kpogan, H. Zahrouni, M. Potier-Ferry, H. Dhia, Int. J. Mater. Form. 10, 389 (2017)

[8] X.C. Yang, X.L. Ma, J. Moering, H. Zhou, W. Wang, Y.L. Gong, J.M. Tao, Y.T. Zhu, X.K. Zhu, Mater. Sci. Eng. A 645, 280 (2015)

[9] L. Chen, F.P. Yuan, P. Jiang, J.J. Xie, X.L. Wu, Mater. Sci. Eng. A 694, 98 (2017)

[10] X.C. Wang, Q.A. Yang, X.Z. Du, Z.Y. Jiang, Int. J. Miner. Metall. Mater. 17, 608 (2010)
[11] J.Y. Jung, Y.T. Im, J. Mater. Process. Technol. 96, 163 (1999)

[12] J.L. Sun, Y. Peng, H.M. Liu, J. Iron, Steel Res. Int. 17, 11 (2010)

[13] A. Steinboeck, G. Mühlberger, A. Kugi, IFAC Proc. Vol. 47, 10646 (2014)

[14] H. Asgari, A.G. Odeshi, J.A. Szpunar, L.J. Zeng, E. Olsson, Mater. Charact. 106, 359 (2015)

[15] F. Ning, X. Zhou, Q. Le, X. Li, Y. Li, Mater. Today Commun. 24, $101129(2020)$

[16] B.Q. Xiao, J.F. Song, A.T. Tang, B. Jiang, W.Y. Sun, Q. Liu, H. Zhao, F.S. Pan, J. Mater. Process. Technol. 280(12), 116611 (2020)

[17] B. Zeng, Dissertation, Chongqing University, 2017.

[18] D. Luo, H.Y. Wang, L.G. Zhao, C. Wang, G.J. Liu, Y. Liu, Q.C. Jiang, Mater. Charact. 124, 223 (2017)

[19] I.B. Ucel, E. Kapan, O. Turkoglu, C.C. Aydiner, Int. J. Plast. 118, 233 (2019)

[20] J. Koike, R. Ohyama, Acta Mater. 53, 1963 (2005)

[21] M.W. Vaughan, W. Nasim, E. Dogan, J.S. Herrington, G. Proust, A.A. Benzerga, I. Karaman, Acta Mater. 168, 448 (2019)

[22] N.L. Li, G.J. Huang, X.Y. Zhong, Q. Liu, Mater. Des. 50, 382 (2013)

[23] S.S.S. Kumar, B. Pavithra, V. Singh, P. Ghosal, T. Raghu, Mater. Sci. Eng. A 747, 1 (2019)

[24] Z.Y. Xiao, X.Y. Yang, J. Wang, Z.W. Fang, C.F. Guo, D.X. Zhang, Y. Yang, X.K. Zhang, J. Alloys Compd. 712, 268 (2017)

[25] Z. Yan, D. Wang, X. He, W. Wang, H. Zhang, P. Dong, C. Li, Y. Li, J. Zhou, Z. Liu, L. Sun, Mater. Sci. Eng. A 723, 212 (2018)

[26] M. Calcagnotto, D. Ponge, E. Demir, D. Raabe, Mater. Sci. Eng. A 527, 2738 (2010) 